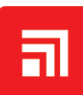 CHITKARA \\ Journal of Nuclear Physics, Material Sciences, Radiation and Applications

\section{Effects of Gamma Irradiation on Curcumin}

\author{
E. Islas-Ortiz ${ }^{1,4 *}$, E. O. Reyes-Salas ${ }^{1 *}$, A. Negrón-Mendoza ${ }^{2}$, A. L. Meléndez-López ${ }^{3}$, A. M. Reyes-Salas ${ }^{3}$, G. Reyes-García ${ }^{1,4}$, J. A. Cruz- \\ Castañeda $^{2}$ and E. Madrigal-Lagunas ${ }^{1}$ \\ ${ }^{1}$ Faculty of Chemistry, National Autonomous University of Mexico, UNAM \\ ${ }^{2}$ Institute of Nuclear Sciences, National Autonomous University of Mexico, UNAM \\ ${ }^{3}$ Institute of Geology, National Autonomous University of Mexico, UNAM \\ ${ }^{4}$ Master's and Doctoral Program in Chemical Sciences, UNAM University Cd., México-04510, D. F. México \\ *Email: islasortize@gmail.com; octavio_reyessalas@yahoo.de
}

\section{ARTICLE INFORMATION}

Received: October 10, 2019

Accepted: January 24, 2020

Published online: February 28, 2020

Keywords:

Electrochemical, Curcumin, Gamma Irradiation

DOI: $10.15415 /$ jnp.2020.72012

\section{ABSTRACT}

In this study, remnants concentrations of curcumin in Curcuma longa (organic turmeric powder) were determined after it was exposed to irradiation doses of 1, 2 and $3 \mathrm{kGy}$. Curcumin analysis was performed using the analyte-sensitive impulse differential polarography technique (LOD: $0.621 \mathrm{ppm}$ and LOQ: $2.130 \mathrm{ppm}$ ). The results obtained showed a decreasing concentration of curcumin as a function of the irradiation dose. This reduction is low in terms of affecting the product's quality with respect to its concentration.

\section{Introduction}

\subsection{Ionizing Radiation in Food}

The application of ionizing irradiation in food has been developed over the past 60 years [1]. It has been applied to a variety of food products, such as meat, poultry, dry ingredients, stored grains and spices. The main potential value of ionizing (gamma) irradiation for the consumer is in food security by reducing pathogens [2] .

\subsection{Curcuma Longa and Curcumin}

Curcuma longa is a plant of Asian origin that has been used in different forms (for coloring and food seasoning) since ancient times. Currently, this plant's ground rhizome is used to aromatize and color food products [3].

In Curcuma longa, the most important chemical components are a group of compounds called curcuminoids (natural antioxidants), which includes curcumin, the majority compound within the rhizome (3-8\%) [4].

Several analytical techniques with high sensitivity can be used to analyze curcumin. Among them are electrochemical techniques (voltamperometry and polarography) [5], which are very sensitive and easy to reproduce without large variations in its matrix.

\section{Experiment}

\subsection{Electrochemical System for the Determination of Curcumin}

The electrochemical system (differential pulse polarography) used to determine the standard compound curcumin was a 797 VA Computrace potentiostat coupled with Metrohm software V. 1.02, which had a dropping electrode arrangement of mercury (working electrode), an $\mathrm{Ag} / \mathrm{AgCl}$ electrode in $\mathrm{KCl} 3 \mathrm{~mol} / \mathrm{L}$ (reference electrode) and a platinum electrode (auxiliary electrode). This was performed with the following conditions suitable for the system:

Start potential (V): -0.800

End potential (V): -1.700

Voltage step (V): 0.005

Voltage step time(s): 1.000

Sweep rate $(\mathrm{V} / \mathrm{s}): 0.005$

Pulse amplitude (V): -0.050

Pulse time(s): 0.040

Polarographic curves were performed with $10.000 \mathrm{~mL}$ of electrolyte-support $\mathrm{LiClO}_{4}$ at $0.25 \mathrm{~mol} / \mathrm{L}$ ( $70 \%$ ethanol and $30 \%$ deionized water) in the work cell. 


\subsection{Gamma Radiation of Curcuma Longa}

Three grams of the dry natural sample (organic turmeric powder) in glass containers were irradiated at doses of 1,2 and 3 kGy by means of the Gamma-Beam 651 PT equipment, at Instituto de Ciencias Nucleares, UNAM.

\subsection{Electrochemical System for the Determination of Curcumin in the Irradiated Ground Rhizome}

The curcumin concentration in the rhizome of Curcuma longa (organic turmeric powder) was determined with the electrochemical system (differential impulse polarography), with the same parameters as with the curcumin standard. For irradiated samples, this parameter is between 0.0200 $0.0400 \mathrm{~g}$ at a $10.000 \mathrm{~mL}$ capacity $(70 \%$ ethanol and $30 \%$ deionized water), with an addition of $1500 \mu \mathrm{L}$ in the cell. The concentration was determined using the standard addition method for each sample.

\section{Results and Discussion}

\subsection{Limits to the Quantification and Detection of Standard Curcumin}

The electrochemical study (differential pulse polarography) showed a reduction signal with $\mathrm{E}_{\text {peak }}$ (peak of the current intensity) of $-1.100 \mathrm{~V}$ (with established conditions) proportional to the additions of standard curcumin $\left(2.620 \times 10^{-3} \mathrm{~mol} / \mathrm{L}\right)$ in $70 \%$ ethanol and $30 \%$ deionized water (Figure 1).

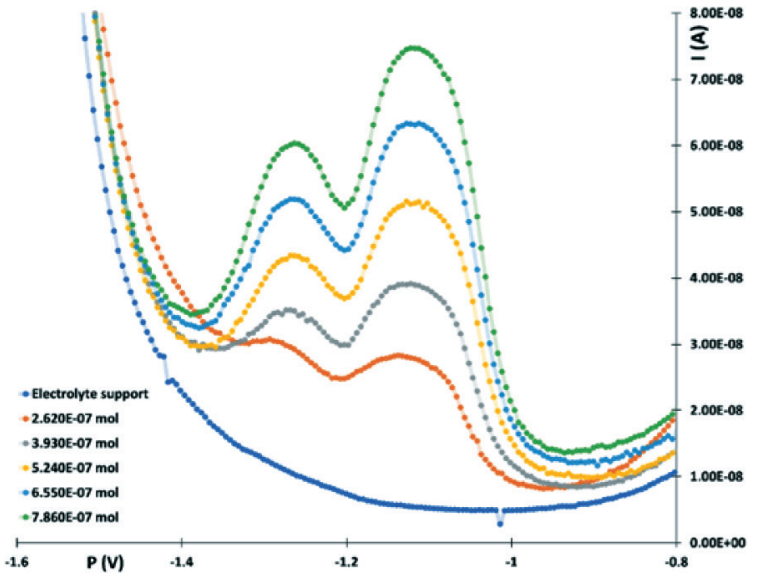

Figure 1: Polarograms (differential pulse polarography) (potential $[\mathrm{V}]$ vs. current intensity $[\mathrm{A}]$ ) of the curcumin standard. Work conditions: start potential (V): -0.800 ; end potential $(\mathrm{V}):-1.700$; voltage step $(\mathrm{V})$ : 0.005 ; step voltage time $(\mathrm{s})$ : 1.000 ; sweep rate (V/s): 0.005; pulse amplitude (V): -0.050 ; and pulse time(s): 0.040 , with $10.000 \mathrm{~mL}$ of electrolyte-support $\mathrm{LiClO}_{4}$ at 0.25 $\mathrm{mol} / \mathrm{L}$ (70\% ethanol and $30 \%$ deionized water).
With the $I_{\text {peak }}$ data of polarograms (Figure 1) a standard curve is constructed (Figure 2) (standard curcumin concentration $[\mathrm{mol}]$ vs $\mathrm{I}_{\text {peak }}(\mathrm{A})$ at $-1.100 \mathrm{~V}$ ) (Figure 2), where LOD and LOQ are obtained.

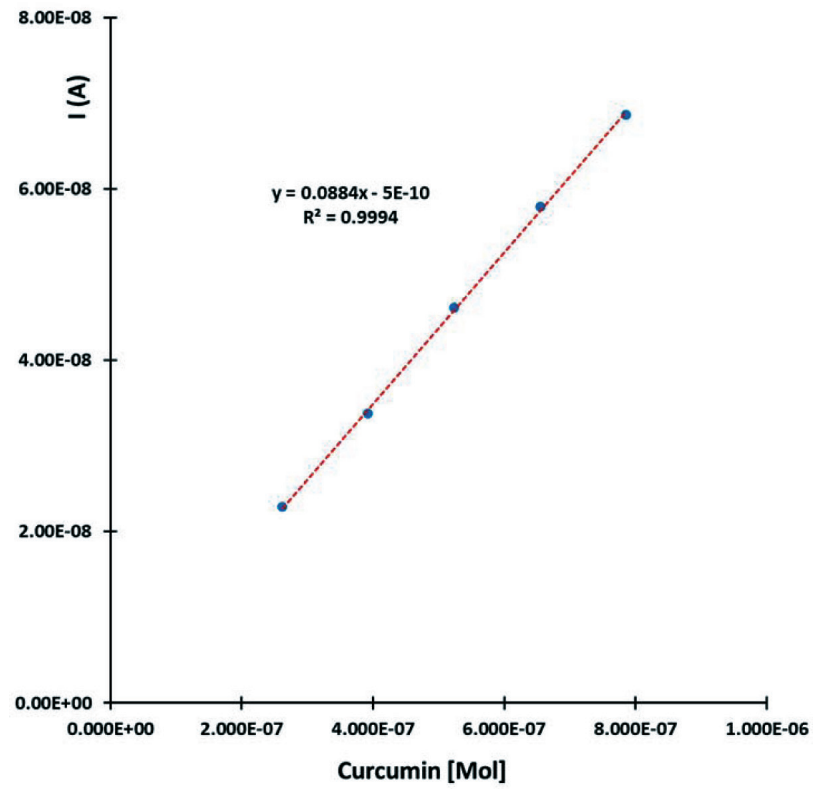

Figure 2: Standard curve of curcumin [mol] vs $E_{\text {peak }}$ for LOD and LOQ determination.

The results obtained are as follows:

Limit of detection (LOD): $0.621 \mathrm{ppm}\left(1.735 \times 10^{-8}\right.$ mol curcumin)

Limit of quantification (LOQ): $2.130 \mathrm{ppm}\left(5.783 \times 10^{-8}\right.$ mol curcumin)

The proposed system for curcumin determination denotes its sensitivity and precision to determine changes in curcumin concentration.

\subsection{Determination of Curcumin in Irradiated Rhizome Samples}

Electrochemical determination (polarography impulse difference). Figure 3 shows an example for determination of curcumin: $1500 \mu \mathrm{L}$ for the organic turmeric powder irradiated at $1 \mathrm{kGy}(0.0282 \mathrm{~g}$ in $10.000 \mathrm{~mL}$ of $70 \%$ ethanol and $30 \%$ deionized water). Other samples were irradiated at $0,1,2$ and $3 \mathrm{kGy}$ and the same procedure was made.

\subsection{Effect of Irradiation on Curcumin}

Determining the effect of irradiation doses on curcumin concentration in organic turmeric powder using polarogram analysis; this analysis is by creating a standard addition curve (Figure 4), where curcumin concentration [mol] vs $I_{\text {peak }}(A)$ (at $-1,100 \mathrm{~V})$ is graphed, being the first point of the graph $(\mathrm{X}=0)$ corresponding to the sample and the substitutions corresponding 
to the curcumin standard, obtaining a linearity with respect to the concentrations.

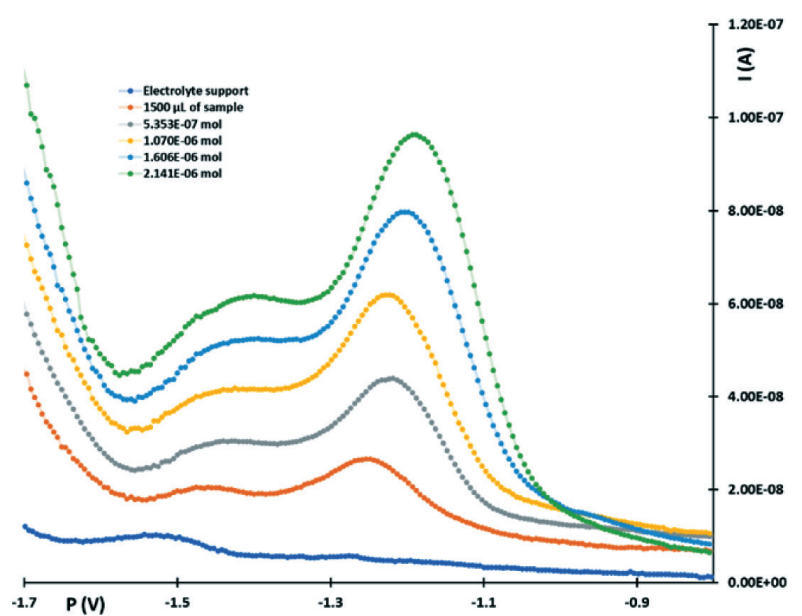

Figure 3: Polarograms (polarography impulse difference) (potential $[\mathrm{V}]$ vs. current intensity $[\mathrm{A}]$ ) of organic turmeric powder irradiated at $1 \mathrm{kGy}(0.0282 \mathrm{~g}$ in $10.00 \mathrm{~mL}$ of $70 \%$ ethanol and $30 \%$ deionized water) and standard additions of curcumin. Work conditions: start potential $(\mathrm{V})$ : -0.800 ; end potential $(\mathrm{V})$ : -1.700 ; voltage step $(\mathrm{V})$ : 0.005 ; step voltage time $(\mathrm{s}): 1.000$; sweep rate $(\mathrm{V} / \mathrm{s}): 0.005$; pulse amplitude (V): -0.050 and pulse time(s): 0.040, with $10.000 \mathrm{~mL}$ of electrolyte-support $\mathrm{LiClO}_{4}$ at $0.25 \mathrm{~mol} / \mathrm{L}(70 \%$ ethanol and $30 \%$ deionized water).

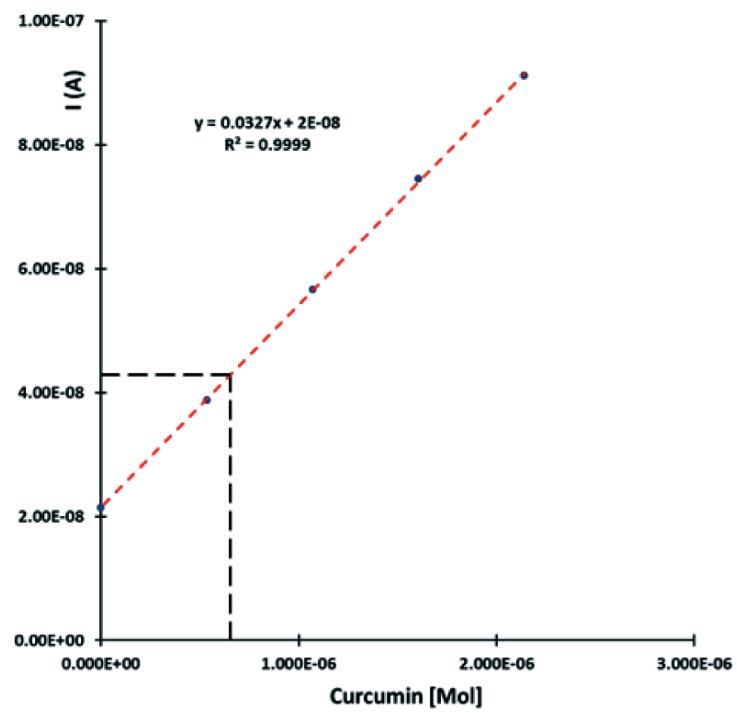

Figure 4: Standard addition curve of organic turmeric powder with $1 \mathrm{kGy}$ irradiation $(1500 \mu \mathrm{L}$ of $0.0282 \mathrm{~g}$ in $10.000 \mathrm{~mL}$ of $70 \%$ ethanol and $30 \%$ deionized water), concentrations of curcumin vs. $I_{\text {peak. }}$

The concentration of curcumin in the irradiated samples was calculatedas percentage ratio by mass (Table 1); this data can be denoted (Figure 5) as a change in curcumin loss with increasing ionizing radiation.
Table 1: Results of the electrochemical analysis (differential impulse polarography) of curcumin concentration with respect to ionizing dose ratio.

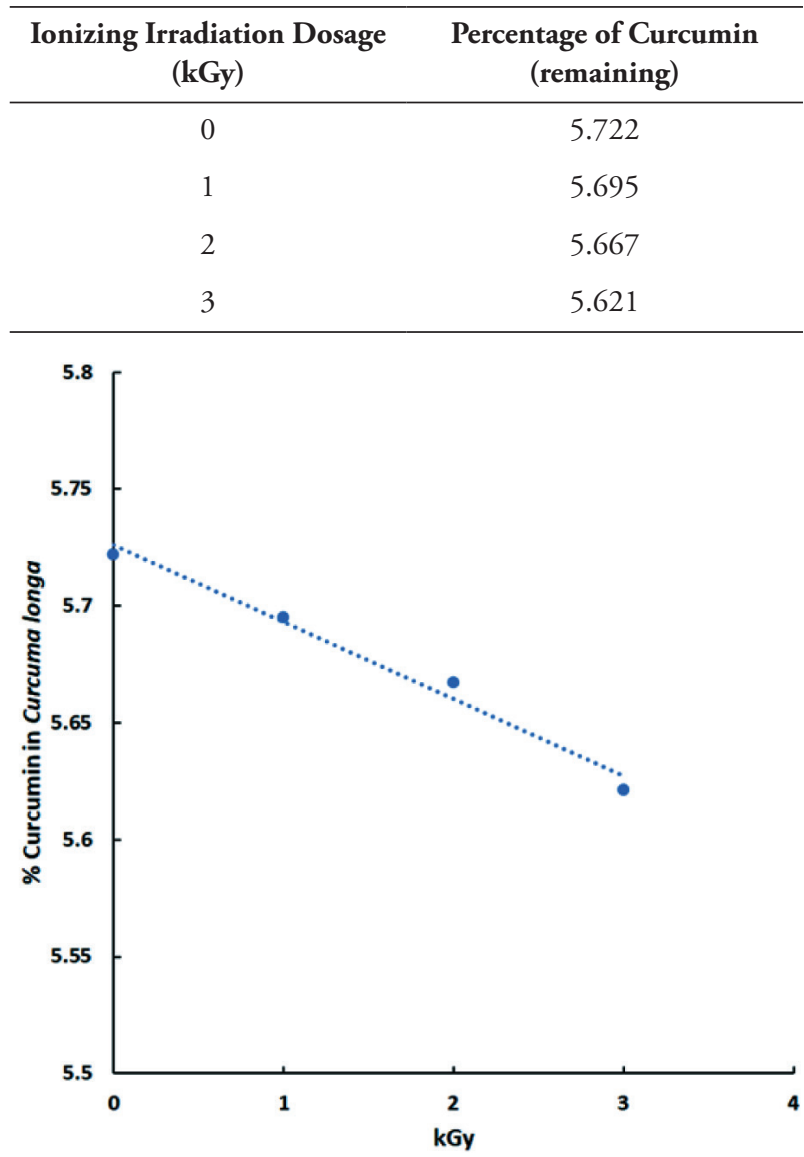

Figure 5: Effect of irradiation dose in the concentration of curcumin in organic turmeric powder.

\section{Conclusions}

The effects of ionizing radiation (gamma) on the concentration of curcumin in the ground rhizome of Curcuma longa was studied by means of an electrochemical system. The results showed that the curcumin concentration had minimal variation, and that radiation does not affect the quality of the product.

These results can provide information on the effects of ionizing radiation within a natural system with high sensitivity.

\section{Acknowledgments}

The support from Programa de Maestría y Doctorado en Ciencias Químicas-UNAM and CONACYT for the support of the CVU scholarship: 364908. 


\section{References}

[1] Molins, R. Food irradiation: Principles and applications. edited by Wiley/Interscience (New York, 2001).

[2] J. Farkas, Trends in Food Science \& Technology 17, 148 (2006).

https://doi.org/10.1016/j.tifs.2005.12.003
[3] A. Benavides, R. E. Hernández, H. Ramirez, and A. Sandoval. Tratado de Botánica Económica Moderna. Universidad Autónoma Agraria Antonio Narro. Buenavista, Saltillo, Coah., México (2010).

[4] F. Tayyem, D. Heath, K. Al-Delaimy and L. Rock, Nutrition and Cancer 55, 126 (2006). https://doi.org/10.1207/s15327914nc5502_2

[5] G. Reyes-Garcia, Q. thesis, UNAM, 2019. 


\section{Journal of Nuclear Physics, Material Sciences, Radiation and} Applications

Chitkara University, Saraswati Kendra, SCO 160-161, Sector 9-C, Chandigarh, 160009, India

Volume 7, Issue 2

February 2020

ISSN 2321-8649

Copyright: [@ 2020 E. Islas-Ortiz et al.] This is an Open Access article published in Journal of Nuclear Physics, Material Sciences, Radiation and Applications (J. Nucl. Phy. Mat. Sci. Rad. A.) by Chitkara University Publications. It is published with a Creative Commons Attribution- CC-BY 4.0 International License. This license permits unrestricted use, distribution, and reproduction in any medium, provided the original author and source are credited. 